\title{
Akut Böbrek Hasarı Olgusunda Metformin ile İlişkili Laktik Asidoz
}

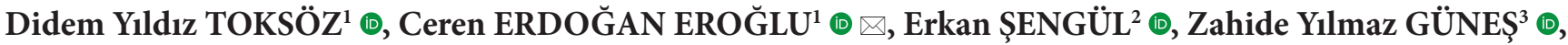 Burcu Çilek BALIMRE ${ }^{1}$ (1)}

'Sağlık Bilimleri Üniversitesi, Kocaeli Derince Sağlık Uygulama ve Araştırma Merkezi, İç Hastalıkları Kliniği, Kocaeli, Türkiye ${ }^{2}$ Sağlık Bilimleri Üniversitesi, Kocaeli Derince Sağlık Uygulama ve Araştırma Merkezi, Nefroloji Kliniği, Kocaeli, Türkiye ${ }^{3}$ Sağlık Bilimleri Üniversitesi, Kocaeli Derince Sağlık Uygulama ve Araştırma Merkezi, Nöroloji Kliniği, Kocaeli, Türkiye

Bu makaleye yapılacak atıf: Toksöz DY ve ark. Akut Böbrek Hasarı Olgusunda Metformin ile İlişkili Laktik Asidoz. Turk J Diab Obes 2021;2: 233-236.

ÖZ

Amaç: Metformin, tip 2 diyabetin birinci basamak tedavisinde önerilen bir oral anti-diyabetik ajandır. Laktik asidoz, nadir gözlenmekle birlikte, yüksek mortalite oranı nedeniyle ilacın en önemli yan etkisidir. Hipoksemi, sepsis, akut ve kronik böbrek hasarı, karaciğer yetmezliği ve kalp yetmezliği metformin ilişkili laktik asidoz (MALA) gelişimini kolaylaştırabilir. Burada akut böbrek hasarı olgusunda gelişen MALA’yı tartışmayı amaçladık.

Olgu: 64 yaşındaki kadın hasta parkinsonizm bulguları nedeniyle nöroloji servisinde takip edilmekteyken üre kreatinin yüksekliği olması üzerine konsülte edildi. Bulantı kusma ve iştahsızlık şikayeti vardı. Vital bulguları stabildi. Sorgulandığında 6 senedir diyabetes mellitus için metformin tedavisi aldığı öğrenildi. Kan gazında artmış anyon açıklı metabolik asidoz ve laktik asit yüksekliği saptandı. Hastada akut böbrek hasarı zemininde gelişen MALA düşünülerek metformin kesildi. Hemodiyalize alındı ve destek tedavi uygulandı. Hastanın böbrek fonksiyonları 1 hafta sonra normale döndü.

Sonuç: Metformin ile tedavi edilen hastaların kontrendikasyonlar açısından takibi MALA gelişiminin önlemesi açısından önemlidir. MALA'da erken tanı ve uygun tedavi morbiditeve mortaliteyi azaltmaktadır

Anahtar Sözcükler: Akut böbrek hasarı, Metformin, Laktik asidoz, Hemodiyaliz

\section{Metformin-Associated Lactic Acidosis in a Case of Acute Kidney Injury}

\begin{abstract}
Aim: Metformin is an oral anti-diabetic agent recommended in the first-line treatment of type 2 diabetes. Although lactic acidosis is rarely observed, it is the most important side effect due to its high mortality rate. Hypoxemia, sepsis, acute and chronic renal injury, hepatic insufficiency and heart failure can precipitate metformin-associated lactic acidosis (MALA). Here, we aimed to discuss MALA in a case of acute kidney injury.

Case: A 64-year-old female patient was hospitalized in the neurology department due to signs of parkinsonism and was consulted due to increased urea and creatinine. She had nausea, vomiting and loss of appetite. Her vital signs were stable. When questioned, it was learned that she had been receiving metformin treatment for diabetes mellitus for 6 years. High anion gap metabolic acidosis and lactic acid elevation were found in blood gas. The patient was considered to have MALA in the setting of acute kidney injury. Metformin was discontinued. Hemodialysis and supportive treatment was administered. Recovery of the patient's renal functions was achieved after a week.
\end{abstract}

Result: Follow-up of patients treated with metformin in terms of contraindications is important to prevent the development of MALA. Early diagnosis, supportive treatment and renal replacement treatments reduce morbidity and mortality in MALA

Keywords: Acute kidney injury, Metformin, Lactic acidosis, Hemodialysis

ORCID: Didem Yıldız Toksöz / 0000-0002-9014-0378, Ceren Erdoğan Eroğlu / 0000-0002-5986-0641, Erkan Şengül / 0000-0003-3461-4740, Zahide Yllmaz Güneș / 0000-0001-6848-9324, Burcu Çilek Balimre / 0000-0001-8000-3380

Yazışma Adresi / Correspondence Address:

DOI: $10.25048 /$ tudod. 868292

\section{Ceren ERDOĞAN EROĞLU}

Sağlık Bilimleri Üniversitesi, Kocaeli Derince Sağlık Uygulama ve Araştırma Merkezi , Kocaeli, Türkiye

Tel: 0 (262) 3178000 • E-posta: ceren.erdogan@hotmail.com

Geliş tarihi / Received : :27.01.2021 Revizyon tarihi / Revision : 03.06.2021 Kabul tarihi / Accepted : 30.06 .2021 


\section{GİRIŞ}

Metformin, tip 2 diyabet yönetiminde birinci basamak tedavi olarak önerilen biguanid grubu oral antidiyabetik bir ilaçtır (1). Metformin kullanan hastalarda en sık bulantı, ishal ve abdominal kramp gibi gastrointestinal yan etkiler gözlenmektedir. Laktik asidoz ise ilacın nadir ancak yüksek mortalite oranına sahip en önemli yan etkisidir. Metformin ilişkili laktik asidoz (MALA) insidansının yıllık 100000 hastada 3-6 arasinda olduğu tahmin edilmektedir $(2,3)$. MALA görülen vakaların mortalite oranının ise $\% 25-\% 50$ arasında bildirilmiștir (4). Erken tanı ve tedavinin zamanında başlanması morbidite ve mortaliteyi azaltmaktadır. Burada akut böbrek hasarı zemininde MALA gelişen olgumuzu tartışmayı amaçladık.

\section{OLGU SUNUMU}

64 yaşında kadın hasta, yeni gelişen parkinsonizm bulgularının etiyolojisinin araştırılması amacıyla nöroloji servisinde takip edilmekteyken üre ve kreatinin yüksekliği ile konsülte edildi. Son 2 gündür iştahsızlık, bulantı ve kusma şikayetleri mevcuttu. Özgeçmişinde 6 senedir tip 2 diyabetes mellitus olduğu ve tedavide sadece metformin 2x1000 mg/ gün aldığı öğrenildi. Ayrıca duygu durum bozukluğu nedeniyle risperidon $1 \mathrm{mg} \mathrm{1x1/gün,} \mathrm{sodyum} \mathrm{valproat} 300 \mathrm{mg}$ 2x1/gün kullanmaktaydı. Hastanın yatışında kullanmakta olduğu risperidon ve valproat parkinsonizm bulgularına neden olabileceği için kesilip psikiyatri önerisiyle yerine trazodon tedavisine geçilip takip planlanmıştı. Öncesinden bilinen böbrek yetmezliği, kardiyovasküler hastalık öyküsü, kontrast madde alımı, non-steroid antiinflamatuar ve diğer nefrotoksik ilaç kullanımı yoktu. İdrar miktarında azalma mevcut değildi. Kan basınc1: 130/60 mmHg, nabız: 90/dak., ateş: $36,7^{\circ} \mathrm{C}$, solunum sayısı: $16 /$ dak, oksijen satürasyonu: \%99 idi. Fizik muayenede bilinç açık koopere ve oryanteydi. Her iki elde istirahat tremoru vardı. Bilateral dişli çark ve rijidite mevcuttu. Deri turgor tonus normaldi ve pretibial ödem saptanmadı. Diğer sistem muayeneleri olağandı. Hastanın ilk değerlendirmedeki laboratuvar parametreleri Tablo 1'de yer almaktadır. Elektrokardiyografide normal sinüs ritminde hız 90/dk olup iskemik değişiklik saptanmad. Posteroanterior akciğer grafisinde bilateral kostofrenik sinüsler açık, kardiyotorasik oran normal olup infiltrasyona ve efüzyona rastlanmadı. Ultrasonografide karaciğer ve dalak boyut ve ekosu normaldi. Bilateral böbrekler boyut, lokalizasyon, parankim ve sinüs ekoları ile parankim kalınlığ 1 normaldi. Pelvikalisiyel yapılarda dilatasyon ve taş izlenmedi. Mesane duvar kalınlığı ve lümen ekosu doğal olup lümende taş veya kitle saptanmadı. İdrar yolu enfeksiyonu (IYE) nedeniyle seftriakson $2 \mathrm{x} 1 \mathrm{gr}$ alıyordu. İYE dışında başka bir akut böbrek hasarı $(\mathrm{ABH})$ nedeni de saptanmadı. Hastada ABH zemininde MALA düşünülerek metformin kesildi. Bir ay önceki HbA1c değeri $\% 5$ olan hastaya yakın kan şekeri takibi yapıldı. Parmak ucu kan şekeri ortalama $<180 \mathrm{mg} / \mathrm{dL}$ olarak seyrettiği için insülin tedavisi uygulanmadı. 2 gün ardışık hemodiyalize alındı. Bulantı kusma şikâyetleri geçti. Takibi süresinde her gün yaklaşık 1000-1500 cc idrar çıkışı olan hastaya aldığı çıkardığı takibi dengede kalacak şekilde hidrasyon verildi. Hastaya nöroloji tarafından parkinson için dozu tedricen artırılmak üzere pramipeksol 1 gr 3xl ve levodopa+benserazide $125 \mathrm{mg}$

Tablo 1. Laboratuvar parametreleri

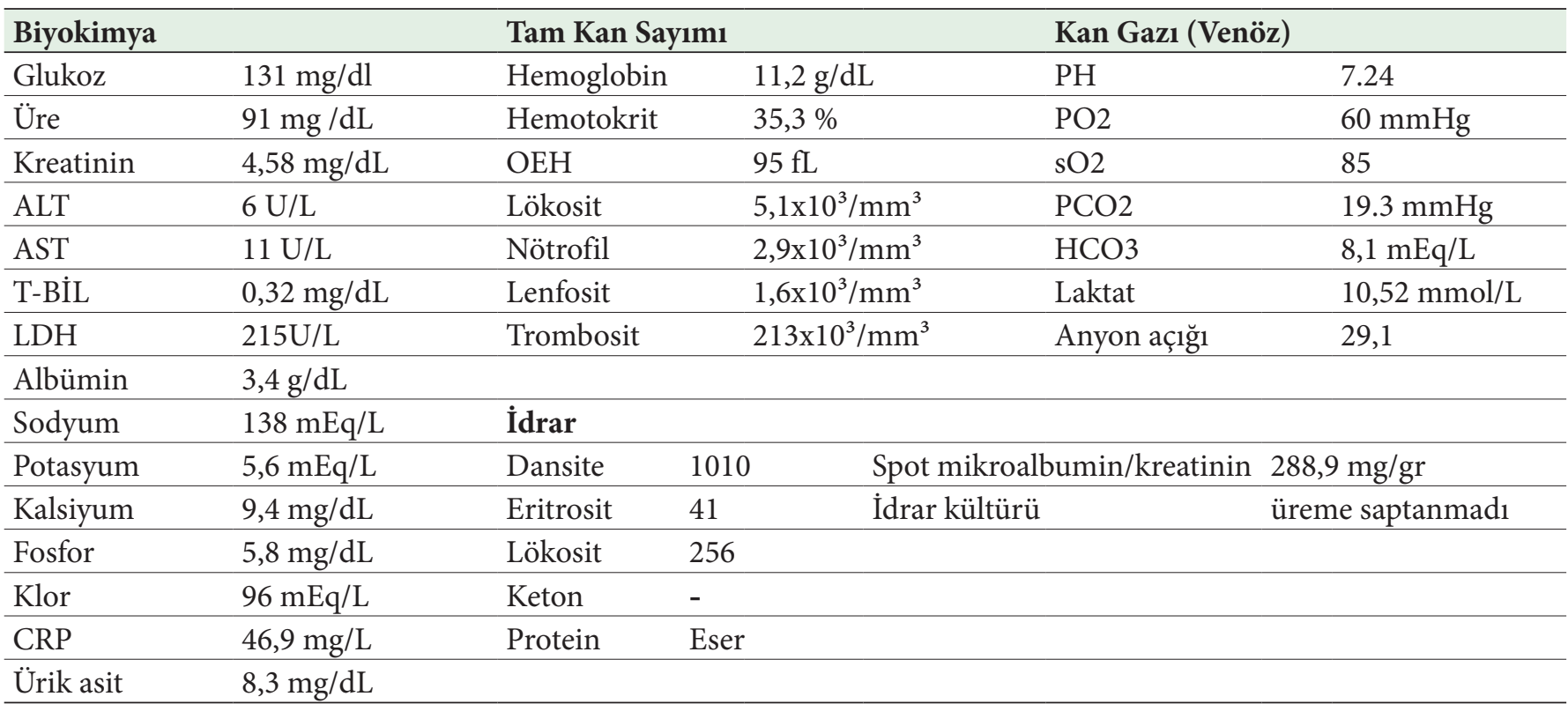

ALT: Alanin aminotransferaz, AST: Aspartat aminotransferaz, T-BİL: Total bilirubin, LDH: Laktat dehidrogenaz, CRP: C-Reaktif protein, OEH: Ortalama eritrosit hacmi 
$3 \times 1 / 2$ olarak başlandı. 1 haftalık takip sonrası üre: $24 \mathrm{mg} / \mathrm{dl}$, kreatinin: 0,8 mg/dl, $\mathrm{pH}: 7,49, \mathrm{PCO}_{2}: 41,3 \mathrm{mmHg}, \mathrm{HCO}_{3}$ : $31,4 \mathrm{mEq} / \mathrm{L}$, laktat: $1,17 \mathrm{mmol} / \mathrm{L}$, anyon açığı: 11,1 saptandı.

\section{TARTISMA}

MALA 7,35'ten düşük kan $\mathrm{pH}$ seviyesi ve $5 \mathrm{mmol} / \mathrm{L}$ 'den fazla arteriyel kan laktat seviyesi ile karakterizedir. MALA gelişen olguların genelinde plazma metformin seviyesi $>5 \mu \mathrm{g} / \mathrm{mL}$ (teröpatik aralık $<2 \mu \mathrm{g} / \mathrm{mL}$ ) saptanmıştır. Böbreklerde proksimal tübüllerden metabolize edilmeden atılan metforminin akut veya kronik böbrek hasarı durumunda kullanılması plazma metformin seviyesini artırarak MALA olușumuna neden olmaktadır $(5,6)$. Bu nedenle, glomerüler filtrasyon hızı (GFH) $<30 \mathrm{ml} / \mathrm{dk} / 1,73 \mathrm{~m}^{2}$ ise metformin kullanımı kontrendikedir. GFH $30-60 \mathrm{ml} / \mathrm{dk} / 1,73 \mathrm{~m}^{2}$ arasinda ise doz azaltılarak dikkatle kullanılması önerilmektedir (1).

Metformin uygun hasta grubunda kullanıldığında yan etki profili olarak güvenilir bir ajandır. Literatürde 70490 metformin kullanan hastanın yer aldığı 347 karşılaştırma1 çalışma ve gözlemsel kohort çalışmasının yer aldığı bir derlemede MALA olgusu tespit edilmemiştir (7). MALA saptanan 559 olgunun incelendiği bir derlemede olguların \%81'inde böbrek hasarı, \%12'sinde şok, \%10'unda karaciğer fonksiyon bozukluğu olmak üzere genelin \%97'sinde en az bir risk faktörü olduğu tespit edilmiștir. 145 olgunun kronik böbrek hasarı öyküsü (GFH $\left.<60 \mathrm{ml} / \mathrm{dk} / 1,73 \mathrm{~m}^{2}\right)$ olmasına rağmen \%60'tan fazla olguda önerilen metformin dozunun üzerinde bir kullanım olduğu saptanmıştır (8).

Dehidratasyon, şok, alkol kullanımı, sepsis, hipoksik durumlar, ileri yaş (yaşa bağlı renal fonksiyonların azalması, akut böbrek yetmezliği açısından risk teşkil eden durumların varlığı) gibi laktik asidoz riskini artıran durumların varlığında metformin kullanımından kaçınılması önerilmektedir (2). İntravenöz sodyum bikarbonat kan pH'ını düzeltmek için kullanılabilir. Ancak hemoglobin disosiasyon eğrisinin sola kayması, sodyum yükünün artması, 'rebound' metabolik alkaloz, karbondioksit üretiminin artması, miyokardiyal kontraktilitenin azalması, bolus enjeksiyon sonrası oluşabilecek refleks vazodilatasyon gibi dezavantajları nedeniyle şiddetli asidoz $(\mathrm{pH}<7.1)$ durumunda dikkatli kullanılması önerilmektedir. Metformin ile tedavi edilen bir hastada, artmış anyon açıklı metabolik asidoz ve laktat yüksekliği saptandığında MALA düşünülmeli, metforminin kesilmesi ve derhâl tedaviye başlanması önemlidir. Hemodiyaliz ve sürekli venövenöz hemodiyafiltrasyon bu hastalarda başariyla uygulanmaktadır $(9,10)$.

Bizim olgumuzda; üre, kreatinin yüksekliği nedenli tarafımıza danışılan hastamızın kan gazı analizini değerlendirdiğimizde yüksek anyon açıklı metabolik asidoz ve laktat yüksekliği ile karşılaştık. Hastada ciddi anemi, kalp yet- mezliği, epilepsi gibi ek faktörlerin olmaması takiplerinde vital parametrelerinin stabil olması hipotansiyon veya saturasyon düşüklügünün eşlik etmemesinden dolayı doku hipoperfüzyonu nedeniyle oluşan tip A laktik asidozdan uzaklaşılmıştır. Hastayı sorguladığımızda 6 senedir terapötik dozda metformin kullanımının olması kullanmakta olduğu sodyum valproatın parkinsonizme neden olabileceğinden dolayı kesilmesi hastada ön planda akut böbrek hasarı zemininde oluşabilecek metformin ilişkili tip B laktik asidoz olabileceğini düşündürmüștür. Ancak hastanemizde sodyum valproat ve metformin seviyelerine bakılamadığ 1 için olgunun ayırıcı tanısının yapılmasında birtakım boşluklar mevcuttur. Olgumuzda $\mathrm{pH}>7,1$ olması ve yukarıda bahsedilen olası dezavantajları nedeniyle intravenöz sodyum bikarbonat verilmedi ve ardışık 2 seans hemodiyalize alındı. Kliniği ve kan gazı düzelen hastanın 1 hafta sonra ise böbrek fonksiyonları normal değerlere döndü.

Tip 2 diyabet yönetiminde birinci basamak farmakolojik tedavide kullanılan temel ilaçlarından birisi olan metforminin, nadir görülmekle birlikte, en ciddi yan etkisi laktik asidozdur. Böbrek hasarı, kalp yetmezliği, karaciğer fonksiyon bozukluğu gibi çeşitli komorbiditeler MALA oluşmasında rol oynamaktadır. Yüksek anyon açı̆̆ olan metabolik asidoz ve yüksek kan laktat konsantrasyonu ile başvuran metformin kullanan hastalarda MALA akla gelmelidir. Mevcut birinci basamak tedavi, hemodiyaliz veya hemodiyafiltrasyon gibi böbrek replasman tedavileridir. Zamanında tanı, hayat kurtarıcı doğru tedaviyi sağlamaktadır. Metforminin takipli hastalarda reçete edilmesi ve kontrendike durumlara dikkat edilmesi MALA gelişimini önleyecektir.

Teșekkür

Yok.

Yazarların Makaleye Katkı Beyanı

Fikir/kavram: Erkan Şengül, Tasarım: Burcu Çilek Balimre, Denetleme/ danışmanlık: Erkan Şengül, Veri toplama ve/veya işleme: Zahide Yılmaz Güneş, Analiz ve/veya yorum: Ceren Erdoğan Eroğlu, Kaynak taraması: Didem Yıldız Toksöz.

\section{Çıkar Çatışması}

Yazarlar arasında çıkar çatışması yoktur.

Finansal Destek

Hiçbir kurum veya kuruluştan finansal destek alınmamıştır.

Etik Kurul Onayı

Olgu sunumu için etik kurul oluru gerekmemiștir. Hastanın onamı alınmıştır.

Hakem Değerlendirmesi

Kör hakemlik süreci yayınlanmaya uygun bulunmuş ve kabul edilmiştir. 


\section{KAYNAKLAR}

1. American Diabetes Association. 9. Pharmacologic approaches to glycemic treatment: Standards of medical care in diabetesd-2020. Diabetes Care. 2020;43(Suppl 1):98-110.

2. Defronzo R, Fleming GA, Chen K, Bicsak TA. Metforminassociated lactic acidosis: Current perspectives on causes and risk. Metabolism. 2016;65(2):20-29.

3. Eppenga WL, Lalmohamed A, Geerts AF, Derijks HJ, Wensing M, Egberts A, De Smet PA, de Vries F. Risk of lactic acidosis or elevated lactate concentrations in metformin users with renal impairment: A population-based cohort study. Diabetes Care. 2014;37(8):2218-2224.

4. Kajbaf F, Lalau JD. Mortality rate in so-called "metforminassociated lactic acidosis": A review of the data since the 1960s. Pharmacoepidemiol Drug Saf. 2014;23(11):1123-1127.

5. Graham GG, Punt J, Arora M, Day RO, Doogue MP, Duong JK, Furlong TJ, Greenfield JR, Greenup LC, Kirkpatrick CM, Ray JE, Timmins P, Williams KM. Clinical pharmacokinetics of metformin. Clin Pharmacokinet. 2011;50(2):81-98.
6. Lalau JD. Lactic acidosis induced by metformin: Incidence, management and prevention. Drug Saf. 2010;33(9):727-740.

7. Salpeter SR, Greyber E, Pasternak GA, Salpeter EE. Risk of fatal and nonfatal lactic acidosis with metformin use in type 2 diabetes mellitus. Cochrane Database Syst Rev. 2010;2010(4):CD002967.

8. Kuan IHS, Savage RL, Duffull SB, Walker RJ, Wright DFB. The association between metformin therapy and lactic acidosis. Drug Saf. 2019;42(12):1449-1469.

9. Finkle SN. Should dialysis be offered in all cases of metforminassociated lactic acidosis? Crit Care. 2009;13(1):110.

10. Balkan B, Demir G, Balkan F, Çetingök H, Atiç E. Metformin ilişkili laktik asidoz; bir olgu nedeni ile literatürün gözden geçirilmesi. Tıp Fakültesi Klin Derg. 2020;3(1):49-53. 